\title{
8
}

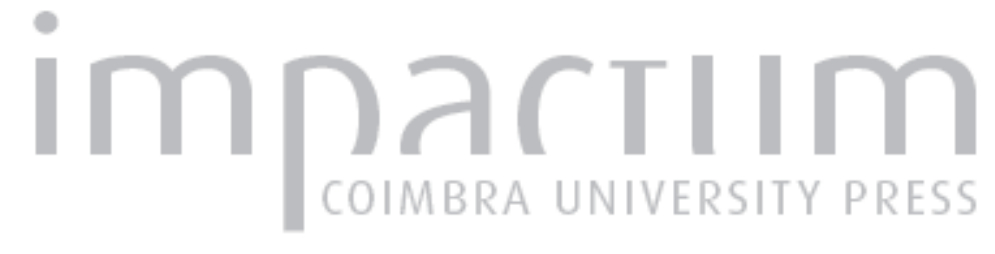

\section{Para uma (re)construção das identidades ou um conceito de Arqueologia Municipal}

Autor(es): Lucas, Maria Miguel

Publicado por: Faculdade de Letras da Universidade de Coimbra

URL persistente:

URI:http://hdl.handle.net/10316.2/37718

DOI:

DOI:http://dx.doi.org/10.14195/1647-8657_45_1

Accessed : $\quad$ 26-Apr-2023 12:19:54

A navegação consulta e descarregamento dos títulos inseridos nas Bibliotecas Digitais UC Digitalis, UC Pombalina e UC Impactum, pressupõem a aceitação plena e sem reservas dos Termos e Condições de Uso destas Bibliotecas Digitais, disponíveis em https://digitalis.uc.pt/pt-pt/termos.

Conforme exposto nos referidos Termos e Condições de Uso, o descarregamento de títulos de acesso restrito requer uma licença válida de autorização devendo o utilizador aceder ao(s) documento(s) a partir de um endereço de IP da instituição detentora da supramencionada licença.

Ao utilizador é apenas permitido o descarregamento para uso pessoal, pelo que o emprego do(s) título(s) descarregado(s) para outro fim, designadamente comercial, carece de autorização do respetivo autor ou editor da obra.

Na medida em que todas as obras da UC Digitalis se encontram protegidas pelo Código do Direito de Autor e Direitos Conexos e demais legislação aplicável, toda a cópia, parcial ou total, deste documento, nos casos em que é legalmente admitida, deverá conter ou fazer-se acompanhar por este aviso.

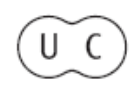




\section{CONIMBRIGA}

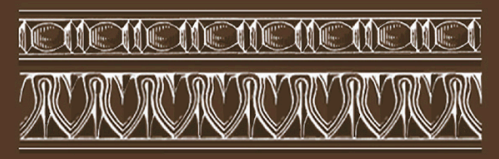

INSTITUTO DE ARQUEOLOGIA

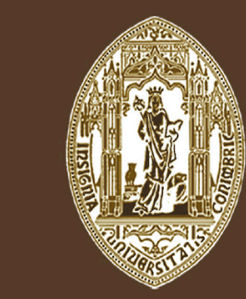

VOLUME XLV - 2006

FACULDADE DE LETRAS UNIVERSIDADE DE COIMBRA 
Maria Miguel LuCAS

Divisão de Património e Museus

Câmara Municipal de Vila Franca de Xira

\section{PARA UMA (RE)CONSTRUÇÃO DAS IDENTIDADES OU UM CONCEITO DE ARQUEOLOGIA MUNICIPAL "Conimbriga" XLV (2006) p. 7-24}

Resumo: Vive-se um tempo cada vez mais efémero. Habita-se um espaço que todos os dias se altera sob os nossos olhos. Sendo o tempo e o espaço os objectos de estudo essenciais ao arqueólogo e as categorias imprescindíveis à identificação, estudo e compreensão dos vestígios e comportamentos humanos de todos os tempos e em todas os espaços, esta assustadora volatilidade coloca problemas acrescidos ao exercício da profissão.

No âmbito hercúleo das competências atribuídas à Arqueologia Municipal, em virtude de um crescente e mediático fenómeno de "consumo do passado", são cada vez mais fortes as solicitações no que respeita à participação nos processos de preservação patrimonial, transmissão de memórias e (re)construção das identidades locais. É ao arqueólogo (mais do que ao historiador) que se pede que construa um discurso do passado e que actue como intermediário entre as vivências desconhecidas do Passado e a realidade Presente. É por ele que passam a preservação dos vestígios do Passado e a sua transmissão às gerações futuras.

A este propósito, discute-se o papel social da arqueologia, defendendo-se a concepção de que as práticas de inventário, gestão, salvaguarda e divulgação de Património Móvel, Arqueológico e Arquitectónico (entre outras componentes patrimoniais relevantes, como a Paisagem ou o Imaterial) não se excluem, antes se complementam na construção das vivências anteriores do espaço, na reconstituição dos comportamentos humanos de cada época, nas dinâmicas a desenvolver para a transmissão futura de memórias e bens culturais. A arqueologia é mais um dos aspectos desse trabalho patrimonial, não devendo 
ser desenvolvido de forma isolada no âmbito concelhio dos projectos culturais e de ordenamento do território.

RESUMÉE: Nous vivons une époque oú le temps devient de plus en plus éphémère, une époque dans laquelle nous habitons dans un espace qui chance chaquejour sous nos yeux.

Étant donné que le temps et l'espace sont les principaux objets d'étude de l'archéologie, tout en constitutant des catégories nécessaires à toute identification, ainsi qu'à l'étude et à la compréhension des vestiges des comportements humains de tous les temps et de tous les espaces, cette effrayante composante volatile pose des problèmes de plus en plus importants, qui deviennent des difficultés à l'exercice de cette profession.

Dans le cadre gigantesque, «herculéen», des compétences attribuées à l'archéologie municipale, les contributions et les sollicitations, en ce qui concerne la participation dans des procès de préservation du patrimoine, la transmission des mémoires et la (re)construction des identités locales, tout en découlant d'un phénomène, croissant et médiatique, tel que la «consommation du passé», ces sollicitations deviennent de plus en plus fortes. Bien plus qu'à l'historien, c'est à l'archéologue que l'on exige un discours sur le Passé, ainsi qu'un rôle d'intermédiaire entre les expériences inconnues du Passé et la réalité du Présent. C'est à lui que revient la responsabilité de la préservation des vestiges du passé, ainsi que la transmission aux générations de l'avenir des connaissances acquises concernant le passé.

La discussion inclue également, à ce propos, le rôle rempli par l'archéologie dans la société actuelle. On y défend une position selon laquelle il est hors de question d'ignorer le travail d'inventaire, la gestion, la sauvegard e et la divulgation aussi bien du patrimoine mobile que du patrimoine archéologique et architectural - ceci parmi d'autres concepts de patrimoine importants, tels le paysage et le patrimoine non matériel. Bien au contraire, ils se complètent par le biais de la restitution des occupations de l'espace dans le passé et la restitution des comportements humains selon chaque époque. De la méme façon, il y a également tout un procès dynamique à développer ayant pour but la transmission future des mémoires et des richesses culturelles. L'archéologie n'est qu'un des aspects, parmi d'autres, du travail développé autour du patrimoine, une besogne à ne pas être envisagée de façon isolée, dans le cadre des projets cultureis et d'aménagement du territoire au sein de chaque commune. 


\title{
PARA UMA (RE)CONSTRUÇÃO DAS IDENTIDADES OU UM CONCEITO DE ARQUEOLOGIA MUNICIPAL
}

\author{
dumque sitim sedare cupit, sitis altera crevit, \\ dumque bibit, visae conreptus imagine formae \\ spem sine corpore amat, corpus putat esse, quod unda est. \\ adstupet ipse sibi vultuque inmotus eodem \\ haeret ut e Pario formatum marmore signum. \\ spectat humi positus geminum, sua lumina sidus \\ et dignos Baccho, dignos et Apolline crines \\ inpubesque genas et eburnea colla decusque \\ oris et in niveo mixtum candore ruborem \\ cunctaque miratur, quibus est mirabilis ipse.
}

Ovidius, Metamorphoses, III, 415-425*.

«Mas, o Narciso era belo?», perguntou o lago. «Quem o poderá saber melhor do que tu?», responderam as Ninfas. «Por nós passou ele sempre mas foi por ti que procurou e se deitou nas tuas margens e olhou para ti.

E foi no espelho das tuas águas que reflectiu a sua própria beleza.» E o lago respondeu: "Mas eu amei Narciso porque enquanto ele se alongava sobre as minhas margens e olhava para mim, em baixo, no espelho dos seus olhos, eu vi sempre a minha beleza reflectida.»

ÓsCAR WILDE, Poemas em prosa.

* In ANDERSON (ed. lit.) 1991.

Deitou-se, e, onde cuidou matar a sede, outra mais forte achou. Como bebia, vio-se n'agua; enlevou-se em tantas graças: julga corpo, o que he sombra, a sombra adora; immovel, fito, como pário busto, pela pasmada sombra está pasmado: debruçado, contempla aquelles ólhos, astros seus; alvas mãos dignas de Baccho; madeixas, que ás de Apollo em nada invejão; faces imberbes, cóllo ebúrneo, bôca linda, estreita, no lírio a côr das rosas: admira tudo enfim, que admirão n'elle. Tradução de A. F. de Castilho (1841). 
Ao explorar o território que, quase como um destino, lhe coube em sortes, o arqueólogo municipal sabe que, com o tempo, nele vai descobrir um longo passado. Tão longo quanto mais antiga for a presença humana nesse espaço. Sabe, também, que o que esperam de si, ao olhar para uma ruína ou para um qualquer objecto "antigos", é que reflicta, como um espelho, as imagens do passado que soube reconstituir. São realidades inalcançáveis, a menos que se saiba ler o que têm para contar do seu mundo, ainda, cada lugar, cada edifício, cada ruína, cada objecto, num tempo que só já pode existir dentro de nós próprios, se o quisermos redescobrir. E, assim, porque as imagens apelam, directamente, à imaginação e, esta, à emoção, para ele, que as descobriu, e para aqueles a quem soube transmitir a mensagem, é agora impossível passar indiferente diante do que aprenderam a valorizar. Porque ficou estabelecida uma dinâmica de afectividades, entre o presente e o passado, entre aquele lugar, as pessoas que o habitam hoje e aquelas que já o habitaram.

\section{Questões de Cultura, Património e Identidade}

Uma Nação identifica-se por possuir uma história, um território, uma língua, uma cultura, bens culturais que simbolizam tudo isso e/ou cada uma dessas coisas: o património cultural nacional é, simbolicamente, aquilo que justifica, face às outras nações, a sua existência, a sua afirmação individual. De bem individual, propriedade específica de um indivíduo ou família, a noção de património dilatou-se para a esfera do colectivo. Património colectivo, nacional, é algo que todo um país porque o possui, porque dele se apropriou - identifica e valoriza como seu e considera, culturalmente - por transmitir valores identitários como um bem a preservar para o futuro.

No contexto da cultura ocidental, a noção de 'efémero' é cada vez mais valorizada do que a de 'eterno'. 'Eterno' é algo de inconcebível que, tendencialmente, se vem remetendo para as esferas da crença ou da ciência. A História e a Arqueologia são, assim, duas das disciplinas científicas cujos objectos de estudo - pelo seu recuo no tempo - dão a sensação de tocar a fímbria da 'Eternidade'. Porque existe um passado - o de há cinquenta anos ou o de há cinco minutos - que sentimos ter acompanhado ao nível do globo: aqui, na China, na Amazónia, na Antárctida, no Iraque. Por outro lado, a modernidade contemporânea 
quase anulou a tendência para a perpetuação da Continuidade. Acredita-se, sente-se, sabe-se que tudo pode mudar, em qualquer momento, ao ponto da destruição irreversível: do território, dos comportamentos, da própria vida. Este cenário de quase impotência face à irreversibilidade da destruição e da Mudança determinou a dilatação da noção de património a proteger. De algo antigo e de grande valor artístico, o conceito de bem cultural passou a abarcar qualquer coisa de material ou imaterial que, integrando uma cultura, dela desapareceu ou corre o risco de desaparecer: tudo o que podemos chamar de "lixos culturais" é, neste momento, património a salvaguardar.

À medida que se vai tomando consciência da voraz destruição dos vestígios materiais e imateriais de um determinado contexto cultural, assiste-se a um fenómeno cada vez mais globalizado de apetência pelo passado: a(s) história(s) do passado vendem livros, programas de televisão, revistas; os personagens da ficção científica vestem e habitam lugares como a imagem que fazemos das sociedades do passado. A sociedade contemporânea parece procurar no passado algo que enraíze no tempo e no espaço o seu presente volátil, algo que ultrapasse no tempo o seu quotidiano efémero, algo que possa transmitir e projectar no futuro. Neste sentido, o património cultural herdado do passado gera curiosidade e paixões e a necessidade do seu conhecimento, estudo e preservação é tema na ordem do dia. Na verdade, por ter existido em épocas de que já não se guardam memórias, por ter perdurado no tempo, todo o património, material ou imaterial, partilha, de alguma forma, do "encanto" que rodeia o conceito de 'Eternidade'.

Por outro lado, numa época em que a globalização está cada vez mais presente, em que predomina a tendência para a unificação, a Diferença sente ter de conquistar o seu lugar. Uma freguesia ou concelho querem, neste contexto, algo que os individualize na globalidade do país. Fazendo parte da história nacional, querem distinguir-se: pelo património local, pelos vestígios singulares legados por um passado que querem (re)conhecer e preservar. Unidade versus Diversidade: Património e Identidade. Estas são as tendências que o arqueólogo municipal deve saber gerir em qualquer território concelhio: a vontade de ser semelhante ao que de mais moderno e 'globalizado' tem o país versus a vontade de se distinguir no conjunto do território nacional. Raramente é fácil gerir este equilíbrio de forças, entre os desígnios de modernidade e futuro - a que tudo pode ser sacrificado - e a vontade de manter vivas a história e tradições locais - elas próprias fruto de uma construção 
anterior que é, muitas vezes, necessário corrigir ou complementar. No entanto, na conjuntura actual, espera-se que o arqueólogo actue como intermediário entre as vivências desconhecidas do passado e a realidade presente: mais do que dirigir intervenções arqueológicas ou estudar materiais, espera-se que aponte os vestígios que alicerçam a história no território, admitindo-se até (mais do que ao historiador) que produza uma "nova história" do concelho.

O objecto de estudo da Arqueologia é, por definição, tudo aquilo que restou dos antigos contextos culturais, os "lixos" que o seu desaparecimento deixou na História, geralmente num passado considerado longínquo. Ambos estudiosos de um espaço e de um tempo, o arqueólogo trabalha - ao contrário do historiador - com um passado sem escrita e sem imagens, até que ele próprio as produza e enquadre nos modelos aceites pelo seu tempo. Enquanto o antropólogo trabalha no estudo de lugares e não lugares habitados por sociedades contemporâneas, o arqueólogo consegue transformar um não lugar (espaço actualmente sem história, sem relações e sem identidade perceptível) num lugar (espaço onde inscreve a identidade, as relações e a história dos que o habitaram). Por se aproximarem da dimensão de 'eterno', a leitura arqueológica da paisagem, da ruína ou do vestígio arqueológicos são o que resta de "exótico" na História, um exotismo que só o arqueólogo pode decifrar e integrar na construção do passado e no estudo sociológico da cultura contemporânea.

\section{Funções da Arqueologia Municipal}

O património cultural é regido pelo Ministério da Cultura, através do Instituto Português de Conservação e Restauro (IPCR), do Instituto Português de Museus (IPM), do Instituto Português de Património Arquitectónico (IPPAR) e do Instituto de Património Arqueológico (IPA), este individualizado dos anteriores por decisão que data de há menos de dez anos. No entanto, desde o aditamento (Lei n. ${ }^{\circ}$ 5-A/2002, de 11 de Janeiro) à Lei-Quadro de Competências das Autarquias Locais (Lei n. ${ }^{\circ}$ 169/99, de 18 de Setembro), que a responsabilidade de inventariar, registar, salvaguardar e valorizar o património cultural não classificado - nele incluídos o património arqueológico - recai, inteiramente, sobre as autarquias locais: o que estas fazem, à medida das suas possibilidades e dos seus critérios individuais, frequentemente sem 
qualquer ajuda ou coordenação da administração central. Ainda assim, o IPM dá apoio técnico à edificação de reservas para as colecções museológicas (muitas delas constituídas, em grande medida, por materiais arqueológicos) e tem programas restritos de financiamento para o estudo, conservação, publicação e divulgação de materiais arqueológicos que integrem as colecções dos museus municipais inseridos na Rede Portuguesa de Museus. A Direcção Geral de Edifícios e Monumentos Nacionais (DGEMN) pode dar apoio técnico e/ou financeiro a alguns processos de recuperação de património, raramente em situações de intervenção arqueológica. Existem diversos programas de financiamento (administrados pelas Comissões de Coordenação e Desenvolvimento Regional (CCDR's) e pelo Instituto de Turismo de Portugal, por exemplo) para a valorização de sítios patrimoniais (entre eles os arqueológicos) a que os municípios podem recorrer. O IPA detém competências sobre toda a actividade arqueológica praticada em território nacional, podendo financiar (em situações excepcionais) projectos de prospecção, intervenção arqueológica ou valorização.

A actuação da Arqueologia tem vindo a ser exigida pela própria sociedade civil, solicitação plasmada na legislação nacional: a Lei de Bases do Património Cultural (Lei n. ${ }^{\circ}$ 107/01, de 8 de Setembro) consagra um capítulo ao património arqueológico e à obrigatoriedade de inventariar, registar e salvaguardar os bens culturais arqueológicos reconhecidos como património nacional; relativamente a todo o património cultural (nele incluído o arqueológico) o mesmo é previsto nos âmbitos específicos das Lei de Bases do Ambiente (Lei n. ${ }^{\circ} 11 / 87$, de 7 de Abril), Lei de Bases do Ordenamento de Território e do Urbanismo (Lei n. ${ }^{\circ}$ 48/98, de 11 de Agosto), Lei Quadro dos Museus (Lei n. ${ }^{\circ} 47 / 2004$, de 19 de Agosto) e Regulamento dos Procedimentos de Avaliação de Impacte Ambiental (Decreto-Lei n. ${ }^{\circ}$ 69/2000, de 3 de Maio); as boas práticas de registo arqueológico estão legisladas através do Regulamento de Trabalhos Arqueológicos (Decreto-Lei n. ${ }^{\circ}$ 270/99, de 15 de Julho; Decreto-Lei n. ${ }^{\circ}$ 187/2000, de 10 de Novembro); existe um conjunto de documentos legais que, paralelamente, regulamentam e precisam os conteúdos da arqueologia subaquática (subordinados à Lei n. ${ }^{\circ} 164 / 97$, de 27 de Junho). A legislação respeita as cartas e convenções internacionais produzidas nesse sentido - nomeadamente a Carta de Cracóvia (versão actualizada da Carta de Veneza) e a Convenção de Malta para a protecção do património arqueológico, subscritas pelo Estado Português - e da sua leitura surge como imediato o facto de 
nenhuma ciência humana e social ter, como a Arqueologia, tão bem regulamentada a sua contribuição para a sociedade civil, muito menos a obrigatoriedade de serem solicitados os seus contributos no âmbito da política de ordenamento e gestão patrimonial. Perante este panorama, dir-se-á, a sociedade portuguesa parece conceder à Arqueologia uma atenção não dispensada a outras disciplinas, igualmente preocupadas com o estudo e a conservação do património.

Efectivamente, é, muitas vezes, o arqueólogo o único representante de uma ciência social e humana chamado a pronunciar-se sobre o passado ("antigo" ou "recente") e sobre a preservação dos seus vestígios no território português: frequentemente cabem, apenas ao arqueólogo (terrestre e/ou subaquático), as responsabilidades de, por exemplo, redigir a componente patrimonial de um estudo de impacte ou acompanhar a recuperação patrimonial de um conjunto edificado. Espera-se dos arqueólogos que actuem como interlocutores nos mais diversos âmbitos disciplinares ou sobrevaloriza-se a componente arqueológica sobre as outras ciências? Em qualquer dos casos, coloca-se, com premência, o problema da sua formação: se a Arqueologia é cada vez mais interdisciplinar e os bons resultados de uma qualquer actividade arqueológica exigem o trabalho conjunto de uma equipa multidisciplinar (dificilmente disponível, quer no contexto estatal, quer no contexto universitário, quer no contexto empresarial, quer no contexto municipal), existe a tendência para a especialização num determinado período cronológico e numa determinada área de análise disciplinar (subaquática, paisagem, materiais cerâmicos, materiais líticos, antropologia física, etc); os curricula universitários integram de forma desigual e parcelar a avaliação de uma componente metodológica "de campo" (investigação, escavação, prospecção, análise de materiais, cenários de actividade profissional); a especialização no domínio, cada vez mais alargado, das diversas áreas da componente arqueológica tem levado a um progressivo distanciamento das disciplinas de História e História de Arte, Arquitectura, Património, Museologia, Antropologia, Geografia, Geologia, cujos objecto e conteúdos integram o pano de fundo contextual e cultural de grande parte das situações profissionais; está longe de estar resolvido o problema da validação profissional dos arqueólogos. Tendo que gerir o conjunto da informação histórica e patrimonial presente no território do concelho, o arqueólogo municipal recorre aos contributos das outras disciplinas apenas na medida das necessidades (pres)sentidas pela sua própria formação, académica e pessoal. 
O conhecimento, estudo, protecção, valorização e divulgação do património cultural constituem um dever do Estado, das Regiões Autónomas e das autarquias locais. Lei n. ${ }^{\circ}$ 107/01, de 8 de Setembro; Art. $3 .^{\circ}$, n. $^{\circ} 3$.

Os órgãos das autarquias locais estabelecerão, no âmbito das competências respectivas, as medidas de protecção e as medidas correctivas que resultem necessárias para a protecção do património

cultural.

Lei n. ${ }^{\circ}$ 107/01, de 8 de Setembro; Art. $40 .^{\circ}$, n. ${ }^{\circ} 2$.

Compete aos municípios a dinamização de uma política patrimonial no interior de cada território concelhio, fazendo cumprir a legislação nacional em vigor. No entanto, raramente se pede a um arqueólogo municipal que actue no sentido da aplicação global das leis em vigor: cada município integra a arqueologia de forma diferente, de acordo com a orgânica interna e as tradições e ambições da política cultural e patrimonial em cada momento, cenário que pode ser alterado em função dos resultados eleitorais, em cada quatro anos. O arqueólogo municipal, com contrato de avença, com contrato a termo resolutivo ou funcionário do quadro, deve cumprir as tarefas que, teoricamente dentro do seu quadro funcional, the são superiormente solicitadas ou autorizadas. No entanto, como todo o técnico superior, deve saber desempenhar as suas funções com autonomia e alertar para a forma mais correcta (do ponto de vista legal, científico, técnico e deontológico) de as cumprir. Neste sentido, todo o arqueólogo municipal pode propor planificações ou tarefas a executar, que possam ser enquadradas nos planos de actividade e investimentos em vigor. Raramente se pode fazer tudo o que se quer, mas é sempre possível começar por ir fazendo.

As funções da Arqueologia Municipal têm vindo a ser definidas à medida que são conhecidos e valorizados os seus contributos para o desenvolvimento cultural dos municípios em que se insere. São aqui sintetizadas as áreas funcionais em que se deve actuar, de acordo com o quadro legal e enquadramento funcional em vigor:

\section{Arqueologia do Território}

O arqueólogo municipal é frequentemente o funcionário da Câmara que melhor conhece o concelho, na medida em que a consciência do território é essencial à planificação das actividades e à emissão de pareceres. 
Num concelho onde não exista esta base de trabalho, a Carta Arqueológica deverá ser a actividade prioritária de um arqueólogo municipal. Onde esta existir, deverá ser verificada a sua eficácia e complementada, na medida do possível, com Cartas de Áreas de Sensibilidade Arqueológica e Cartas do Subsolo Urbano.

A Arqueologia Municipal é frequentemente confundida com ou reduzida a actividades de Arqueologia Urbana - talvez por ter sido essa a frente de trabalho desenvolvida pelos primeiros municípios a integrar arqueólogos nos seus quadros (Braga, Lisboa) - mas a grande maioria dos 308 municípios portugueses integra, para além de áreas urbanas, áreas rurais, florestais, costeiras, ribeirinhas ou de sapal que apresentam problemas específicos de salvaguarda patrimonial, geralmente confiados, quando existe, ao arqueólogo municipal. Quase todos possuem, por outro lado, mais do que um conjunto urbano com interesse patrimonial no seu território, cada um com as suas características específicas, que devem ser inventariadas, cartografadas, definidas e pensadas em termos de salvaguarda, competindo (pelo menos) a vertente arqueológica desta tarefa ao arqueólogo municipal.

A arqueologia não pode ser afastada da vertente patrimonial mais vasta, estando interdependente da Carta de Património, da Carta de Conjuntos Urbanos, das Carta de Risco e da Carta de Áreas Patrimoniais Sensíveis. Porque o arqueólogo se habituou a produzir inventários cartografados, é ele muitas vezes quem executa e gere estes instrumentos, sendo-lhe assim exigidos conhecimentos de património, história, história de arte e do urbanismo, entre outros. É também o arqueólogo o grande responsável pela sua continuidade, uma vez que é ele quem vai complementar a informação disponível, pela adição de sítios inventariados no âmbito de tarefas de prospecção selectiva ou sistemática das porções de território afectadas pelos diversos projectos de loteamento e urbanização, agricultura, florestação, implantação de aterros, estaleiros e infra-estruturas, extracção de inertes, etc, determinadas pela avaliação e minimização de impactes patrimoniais. Podem não ser os arqueólogos municipais a efectuar estes trabalhos, mas os seus resultados devem ser acompanhados e integrados na informação cartográfica e patrimonial disponível.

Uma carta arqueológica deve ser, sempre, transformada numa diacronia da ocupação humana do concelho: os pontos no mapa não dizem nada aos não-arqueólogos ou aos políticos que se pretende que venham a aprovar a continuidade dos projectos de prospecção, inventariação e salvaguarda de património. Com base na sistematização da informação inventariada em cada momento e na sua integração em modelos de análise territorial e da paisagem, pode ir sendo produzida uma história da adaptação das comunidades humanas ao território através dos tempos. Se à 
informação arqueológica se juntar outra informação de base patrimonial (conjuntos urbanos, património viário, arquitectónico, vernacular, histórico, ainda existente ou desaparecido, lendas, tradições) fica-se com uma panorâmica geral das trajectórias históricas no concelho e com uma boa imagem do passado para transmitir aos interlocutores.

Existe a necessidade crescente de se cruzarem os problemas específicos da arqueologia náutica e subaquática com as problemáticas próprias da arqueologia terrestre, começando pela junção dos resultados obtidos nas diversas frentes de trabalho. Esta é uma tarefa que, dependendo da extensão territorial de cada concelho, nunca estará concluída, sobretudo se for desenvolvida - muitas vezes a tempo parcial - por apenas uma pessoa: o arqueólogo municipal.

\section{Arqueologia dos Lugares}

A legislação em vigor define os diversos tipos de intervenção arqueológica conducentes à detecção de sítios arqueológicos: prospecção para inventariação; acompanhamento arqueológico de trabalhos de desaterro/ escavação de emergência; escavação preventiva e de salvaguarda; escavação inserida em projectos de investigação aprovados pelo IPA. Num concelho em que sejam conhecidos sítios arqueológicos e posta em prática a política de património arqueológico prevista pela lei, existe uma tendência para que o seu número aumente de forma exponencial. A lei obriga os proprietários do terreno a financiar os trabalhos arqueológicos que decorram de empreitadas públicas ou privadas, o que geralmente limita a intervenção a um registo rápido das ocorrências, a uma verificação sumária da época cronológica e do contexto funcional, avaliados dentro de quadros e modelos genericamente utilizados e cuja validade científica ainda não foi suficientemente testada. Em casos excepcionais, são efectuadas escavações em área e publicadas monografias do sítio. Em casos ainda mais excepcionais, esses lugares arqueológicos - estruturas em ruína, por definição - são conservados e consolidados, tendo em vista a sua posterior fruição pública. Por vezes, o arqueólogo municipal é contratado expressamente para tratar de um sítio ou de um conjunto de sítios arqueológicos, que o município valoriza sobre todos os outros vestígios patrimoniais.

Deixar sítios arqueológicos a descoberto após a sua escavação é uma responsabilidade grande para quem fica encarregado de manter a sua preservação de forma digna. As quadrículas abertas para escavação devem ser cuidadosamente reenterradas nos casos em que não seja considerada a valorização do sítio. É dispendiosa a manutenção de um sítio arqueológico em condições de visita pública, a de vários sítios num só concelho ainda é mais. Nada que fique aquém dos orçamentos muni- 
cipais, sobretudo se houver quem previna e monitorize constantemente as situações de vandalismo, crescimento de ervas, acumulação de lixos, etc. de forma a não condenar a existência futura de estruturas que subsistiram durante centenas ou milhares de anos até hoje. Deve existir uma política da gestão desses espaços, quer no sentido da sua valorização, quer no sentido da sua salvaguarda: efectuando a classificação legal do sítio quando isso se justifique ou salvaguardando a sua existência no quadro dos Planos Directores Municipais, Planos de Pormenor, Planos de Salvaguarda ou outros regulamentos em vigor no concelho.

Por vezes, os municípios contratualizam com empresas externas os projectos de consolidação de ruínas, valorização e sinalização do sítio, mas é o arqueólogo municipal quem deve zelar pela manutenção futura destes locais, no âmbito dos planos de gestão e das condições disponíveis em cada município. Outras vezes, existem sítios arqueológicos afectos a alguma outra entidade na área do concelho (IPPAR, por exemplo) ou que estão a ser valorizados por empresas privadas. Nestas situações é indispensável a mediação do arqueólogo municipal. Enquanto pessoa no terreno, passará por ele a monitorização das situações a verificar, a gestão e a dinamização do sítio.

Muitas vezes, as escavações arqueológicas - sondagens, ou mesmo escavação - são efectuadas no âmbito de trabalhos de empreitada que não é o arqueólogo municipal que dirige. Os resultados desses trabalhos estão disponíveis no IPA e defende-se que compete ao arqueólogo municipal o enquadramento desses dados na diacronia e sincronias de ocupação humana que estabeleceu para o concelho, sob pena da acumulação sem sentido dos resultados das intervenções efectuadas, até que sejam necessários a algum trabalho de investigação académica

O trabalho não acaba com a escavação e valorização de um sítio arqueológico: é necessário estudar o espólio proveniente da estação, publicá-lo, entender a forma como esse sítio se relacionava com outros dentro do território. $\mathrm{O}$ arqueólogo municipal poderá fazer isso, caso não existam impedimentos legais ou de prioridade científica. Muitas vezes os materiais provenientes de sítios arqueológicos no concelho estão dispersos por vários museus e entidades. O ideal é que sejam criadas condições para serem estudados, conservados e apresentados no concelho. No final, transmitir "aos outros" a informação, à medida que vai sendo (re)construída a imagem destas parcelas do passado. Com base no conhecimento prévio de um Carta Arqueológica, ou na sua elaboração, todos estes objectivos poderão ser previstos no âmbito de um projecto de Plano Nacional de Trabalhos Arqueológicos a sujeitar à aprovação do IPA. 


\section{Arqueologia dos Objectos}

Intervenções arqueológicas de todo o tipo acarretam uma acumulação de materiais arqueológicos de várias épocas, de vários tipos, com diferentes exigências de conservação, que - defende-se - devem permanecer em depósito, na medida do possível, no concelho de que são provenientes. A acumulação nacional de materiais arqueológicos - apesar da tentativa de criar Depósitos Regionais - está longe de ser resolvida e competirá às autarquias gerir estes materiais, estudá-los, proceder à sua conservação (com a indispensável ajuda de técnicos de conservação e restauro) e divulgação. Os Museus Municipais podem ter, a este nível, um excelente papel. Materiais arqueológicos são inventariados e estudados por arqueólogos e, competirá ao arqueólogo municipal - mais do que efectuar ele próprio esse estudo e inventariação (são geralmente em grande número e levaria várias vidas para o fazer) - efectuar os contactos com os especialistas necessários a esses trabalhos. Competir-lhe-á, também, coordenar a inventariação dos materiais em depósito na autarquia e, onde existam Reservas Museológicas, organizar a Reserva de Arqueologia.

O arqueólogo municipal deverá ainda gerir a articulação dos resultados dos trabalhos de estudo e inventariação de materiais com a informação disponível a partir das Cartas de Património e Arqueologia e transmitir as imagens de passado assim produzidas em trabalhos de divulgação (folhetos, revistas da especialidade, publicações monográficas e de síntese, exposições temporárias ou permanentes ou outro qualquer tipo de suporte, percursos de visita) tendo em vista os diversos tipos de público-alvo (escolas, adultos, estrangeiros, especialistas, etc).

\section{Arqueologia de Investigação}

Defende-se que, sob pena de perda de sentido, todo o trabalho efectuado no seio de um município deve ter por base e por objectivo um intuito de investigação. É num âmbito de investigação - querer saber sempre mais para divulgar - que se pode estabelecer uma sequência de trajectórias temporais, traçar uma linha histórica (e arqueológica) da evolução dos comportamentos humanos e da paisagem, atribuir cronologias e funcionalidades a sítios e materiais arqueológicos, elaborar projectos museológicos, programas de dinamização patrimonial, planos de gestão e salvaguarda do património no concelho, itinerários e percursos temáticos de visita. Os resultados obtidos podem não obedecer a todos os requisitos de um programa de investigação académica, mas devem fornecer um fio condutor para a história local do concelho, tendo sempre presentes as limitações que, em cada momento, presidiram à sua construção. 
Para produzir um discurso coerente do passado local, o arqueólogo municipal precisa, talvez mais do que qualquer noutro contexto profissional, de recorrer aos conhecimentos das outras áreas científicas (História, História de Arte, Antropologia, Etnologia, Geografia, Geologia, Arquitectura), nem sempre presentes nos quadros do município ou disponíveis para trabalho conjunto. Neste sentido, o arqueólogo municipal é cada vez mais um técnico especializado de património, competindo-lhe a responsabilidade de chamar a atenção para a necessidade de recorrer às outras disciplinas (até pelo carácter interdisciplinar de que se reveste a prática arqueológica). Como interlocutor privilegiado nos processos de intervenção patrimonial, é muitas vezes a ele que compete gerir e articular a informação acumulada pelas diferentes valências, sintetizando-a e transmitindo-a à população.

\section{Comunicação da Arqueologia}

A comunicação da arqueologia é algo de essencial, talvez a vertente mais relevante da função social do arqueólogo, intérprete especializado dos aspectos "exóticos" do passado, do carácter "eternamente alterado" da cultura humana, da evolução dos espaços e do território, dos significados e tempos da cultura material. Desde que tomem disso consciência, as populações valorizam aquilo que (re)conhecem ter valor, mesmo se esse valor é "apenas" afectivo ou cultural. É indispensável ensinar as comunidades a apropriar-se dos vestígios do passado. Uma vez reconhecidos na paisagem, estes passam a integrar o quotidiano de quem os vê. É preciso que "os outros" sintam e saibam que o património cultural é de todos, direito consagrado pela Lei e pela Constituição. É a comunicação da arqueologia e do património que determina as opções de salvaguarda tomadas em cada momento, em cada época. Cada sociedade escolheu salvaguardar os vestígios patrimoniais que aprendeu, no seu tempo, serem importantes transmitir como parte de si para o futuro.

Especializado no reconhecimento e leitura de paisagens culturais (nas suas diferentes escalas de análise) o arqueólogo é um agente importante no processo da construção e divulgação sociais do passado. Compete-lhe proceder à restituição dessas memórias, contribuindo para a produção das identidades do presente. Neste sentido, defende-se que o arqueólogo municipal deve ser, em todos os momentos, um 'contador de histórias': histórias que apresentem motivos para o enraizamento das populações no espaço que habitam, acrescendo-lhes qualidade de vida; histórias que criem laços de afectividade com o património cultural que aprenderam a reconhecer e valorizar na paisagem. 


\section{O "Arqueólogo Municipal"}

A Associação Profissional de Arqueólogos efectuou, em 2002, um inquérito ao contexto profissional da arqueologia em meio municipal. Dos 308 concelhos existentes, apenas 118 responderam ao inquérito e neles sabemos que existiam, nessa altura, oitenta e nove arqueólogos, em situação precária (52\%) ou definitiva, inseridos em orgânicas diferentes e orientadas para actividades diversificadas (apenas 20\% estruturando serviços autónomos de arqueologia, com equipas constituídas especificamente para o efeito). A norma parece ser a de um arqueólogo municipal, integrado organicamente de forma diferenciada (31\% nas áreas de cultura, $32 \%$ em estruturas museológicas, apenas $3 \%$ em departamentos obras, $3 \%$ em gestão territorial e 5\% em gestão de áreas urbanas/centros históricos). Mais de $60 \%$ não dispunha sequer de gabinete de trabalho ou computador, para não falar de equipamentos e materiais de registo necessários à prática arqueológica. Comparados e corrigidos os resultados com dados das extensões territoriais do IPA, verificou-se que cerca de $63 \%$ dos municípios portugueses não registam mesmo qualquer tipo de prática arqueológica. A realidade, portanto, não parece ser consentânea com a aparente valorização conferida pela legislação em vigor à actividade arqueológica e patrimonial.

Competência recentemente alienada pela administração central, cabe às autarquias locais dotar-se dos meios e criar as estruturas que considerar necessárias para gerir - inventariar, estudar, salvaguardar, recuperar, divulgar - o património cultural inserido na área da circunscrição administrativa que lhe está adstrita. Com esta transferência de responsabilidades, não foi estabelecido nenhum tipo de acréscimo orçamental, nem nenhum quadro normativo, para além do expresso na citada lei de bases do património sobre os critérios e conteúdos das tarefas de gestão de património cultural a cumprir.

Quem verifica se os municípios têm presente esta preocupação nos seus programas de actividades municipais? Quem verifica a qualidade e quantidade dos objectivos de património cultural nesses programas? Ainda assim, um número crescente de concelhos, mercê da pressão da sociedade civil ou da própria sensibilidade para o tema, têm em curso bons programas de salvaguarda e inventário de património arquitectónico e arqueológico, com equipas interdisciplinares e afectando um ou mais arqueólogos a essa tarefa. Raramente, no entanto, os programas municipais abarcam a totalidade das funções de gestão patrimonial que 
lhes estão legalmente acometidas. Na melhor das hipóteses, contrata-se "um" arqueólogo, geralmente com um objectivo de trabalho específico e limitado no âmbito dessas funções: como limitado é, necessariamente, o trabalho que pode desempenhar uma equipa constituída apenas por um técnico superior de arqueologia, geralmente com parcos recursos orçamentais e humanos. Compete-lhe, assim, impressionar as hierarquias ao ponto de alargar a sua equipa de trabalho e as verbas que lhe são afectadas: tem a seu favor o facto de ser o único a saber interpretar as mensagens transmitidas pelos vestígios materiais e estruturais do passado.

\section{Perspectivas de Futuro}

Colocou-se um ênfase, aparentemente despropositado, no tema da Comunicação de Arqueologia. Todo o arqueólogo tende a comunicar um saber que só ele sabe descodificar com a linguagem codificada que utiliza para comunicar com outros arqueólogos. Mas os concelhos são geridos e habitados por não-arqueólogos e as equipas de trabalho que é chamado a gerir e integrar são constituídas por profissionais de outras áreas, cada um deles utilizando a sua linguagem específica: arquitectos, engenheiros civis ou de ambiente, urbanistas, biólogos, paisagistas, geólogos, sociólogos, museólogos. Mais do que em nenhum outro domínio profissional, talvez, o arqueólogo profissional tem de adaptar a sua própria linguagem aos vários públicos que o solicitam: políticos, colegas de outros departamentos, escolas, associações de património, entidades públicas e privadas, comunidade arqueológica e científica. Assim, o arqueólogo municipal é, cada vez mais, um técnico especializado de património cultural que tem de conhecer e adaptar-se à linguagem específica de cada disciplina. A eficácia do seu trabalho depende, em grande medida, da sua capacidade de comunicação e, do sucesso desta, depende a efectiva realização da sua função social.

Como técnico de património, o arqueólogo é frequentemente chamado a pronunciar-se, constituindo um interlocutor habitual dos processos de salvaguarda patrimonial e dinamização cultural. É, frequentemente até, o único interlocutor desses processos, o que - se defende lhe traz uma responsabilidade acrescida.

Os vestígios patrimoniais mais diversos convivem no interior do mesmo território e só farão sentido se foram trabalhados em conjunto. 
Não faz sentido que a Arqueologia trabalhe isolada a um canto do trabalho patrimonial. O património cultural é um grande mundo em que as componentes materiais se interceptam com as imaterialidades da informação oral, das lendas, das tradições locais, em que a história local se revê nas arquitecturas de outros tempos (incluindo as marcas e cicatrizes resultantes de situações de mudança voluntária ou involuntária, apreendidas pelo método arqueológico), nas correntes artísticas escolhidas para dar forma ao recheio de um edifício, ao seu revestimento exterior e interior, e todas estas informações são complementadas pela cultura material (resultante, muitas vezes de uma intervenção arqueológica), a face possível do quotidiano de quem habitava os edifícios. A Arqueologia é, assim, apenas uma parte da componente do trabalho patrimonial. Edifícios, conjuntos urbanos, foram implantados numa paisagem, que, se for questionada nesse sentido, justifica frequentemente a escolha do sítio num determinado contexto cultural e, por isso, deve ser analisada de forma evolutiva, conservando muitas vezes sinais de ter sido habitada nesses (ou noutros) tempos. Todos estes elementos fazem parte da informação necessária ao arqueólogo para elaborar as suas interpretações, produzir sequências de ocupação humana num determinado território, formular sínteses de resultados provisórios. Se souber trabalhar assim, o arqueólogo será um construtor da identidade local, reforçando ou alterando paulatinamente a noção préexistente. Esta é a concepção holística de arqueologia municipal que se defende, uma que tenha por prioridade uma reconstrução global da história local, tendo presente a leitura multiperiodal da paisagem - para o que são essenciais os contributos de outras disciplinas, tanto quanto possível - e tendo como objectivos o enraizamento identitário das populações e a necessidade de salvaguardar para o futuro as memórias e heranças patrimoniais de um território.

São essas - defende-se - as "histórias" que o arqueólogo municipal deve contar. Histórias tão simbólicas e plenas de identidade como a de Eco e Narciso, construída, como toda(s) a(s) História(s) que criamos, através do enquadramento num espaço, num tempo, num determinado contexto cultural, num determinado facto que se narra ou se procura compreender e descrever. São histórias como esta que alicerçam a identidade da Europa e - mediante os efeitos da globalização - de toda a cultura ocidental: Narciso reconhece o seu rosto nas águas; os outros reconhecem-no como sendo Narciso; o lago reconhece-se a si próprio de se ver espelhado nos olhos de Narciso. Se a arqueologia municipal souber 
(re)produzir imagens nítidas e apelativas, o arqueólogo pode levar a que "os outros" se identifiquem com esse(s) tempo(s) e espaço(s) que conta: pode contribuir para que se identifiquem consigo próprios, afinal, enquanto projecções actuais do passado. É ele quem transmite, aos "outros", as memórias guardadas no tempo e no espaço, inscritas num património, material ou imaterial, que é, deveria ser, gerador de identidades e alteridades. É ele, também, muitas vezes, aquele a quem compete zelar pela preservação de património e memórias.

O arqueólogo municipal sabe tudo isto. Mas talvez não saiba, de forma consciente, que corre o risco de se identificar - ele próprio - com os sítios, as paisagens e os objectos que conseguiu repescar do passado, sendo, a um tempo, lago e Narciso apaixonados. Esta pode ser a história de qualquer arqueólogo municipal.

\section{BIBLIOGRAFIA}

Augé, M. 1994a. Le Sens des Autres. Actualité de l'anthropologie. Fayard: Paris.

AugÉ, M. 1994b. Pour une anthropologie des mondes contemporains. Flammarion: Paris.

AugÉ, M. 1998. A Guerra dos Sonhos. Exercícios de Etnoficção. Celta Editora: Oeiras. Bachelard, G. 1957. La poétique de l'espace. P.U.F.: Paris.

Lucas, M. M. \& Ramalho, J. 2001. Diacronias e Sincronias do Património Arquitectónico - Para um Discurso da Identidade, Memórias de Pedra e Cal. Câmara Municipal de Vila Franca de Xira: Vila Franca de Xira.

LuCAs, M. M. 2003. Para uma arqueologia municipal - Vila Franca de Xira. Evolução

2. Centro Português de Geo-História e Pré-História: Lisboa.

LuCAS, M. M. 2005. Vila Franca de Xira: uma experiência de arqueologia e património,

Cartas Arqueológicas - do inventário à salvaguarda e valorização do património (Coord. A. M. Silva). Câmara Municipal de Arouca: Arouca.

OviDE 1980. Les Methamorphoses. Société d'édition «Les Belles Lettres»: 6. ${ }^{a}$ ed.: Paris. Ovidio 1841. As Methamorphoses de Publio Ovidio Nasão. Imprensa Nacional: Lisboa

(tradução de António Feliciano de Castilho).

Ovidivs 1993. Metamorphoses. W. S. Anderson: Stugartiae et Lipsiae.

Pratt, H. 2000. Corto Maltese - Les Celtiques. Casterman: Borgaro.

Rowland, R. 1987. Antropologia, História e Diferença. Alguns aspectos. Afrontamento: Porto.

Silva, A. M. 1997. Das Autarquias aos Profissionais da Arqueologia: Perspectivas da Sociedade Civil, $1{ }^{\circ}$ Colóquio de Gestão do Património Arqueológico (Arkeos $\left.n .{ }^{\circ} 1\right)$. CEIPHAR (Instituto Politécnico de Tomar): Tomar.

Wilde, O. 2003. Poemas em prosa. Cavalo de Ferro: Lisboa. 

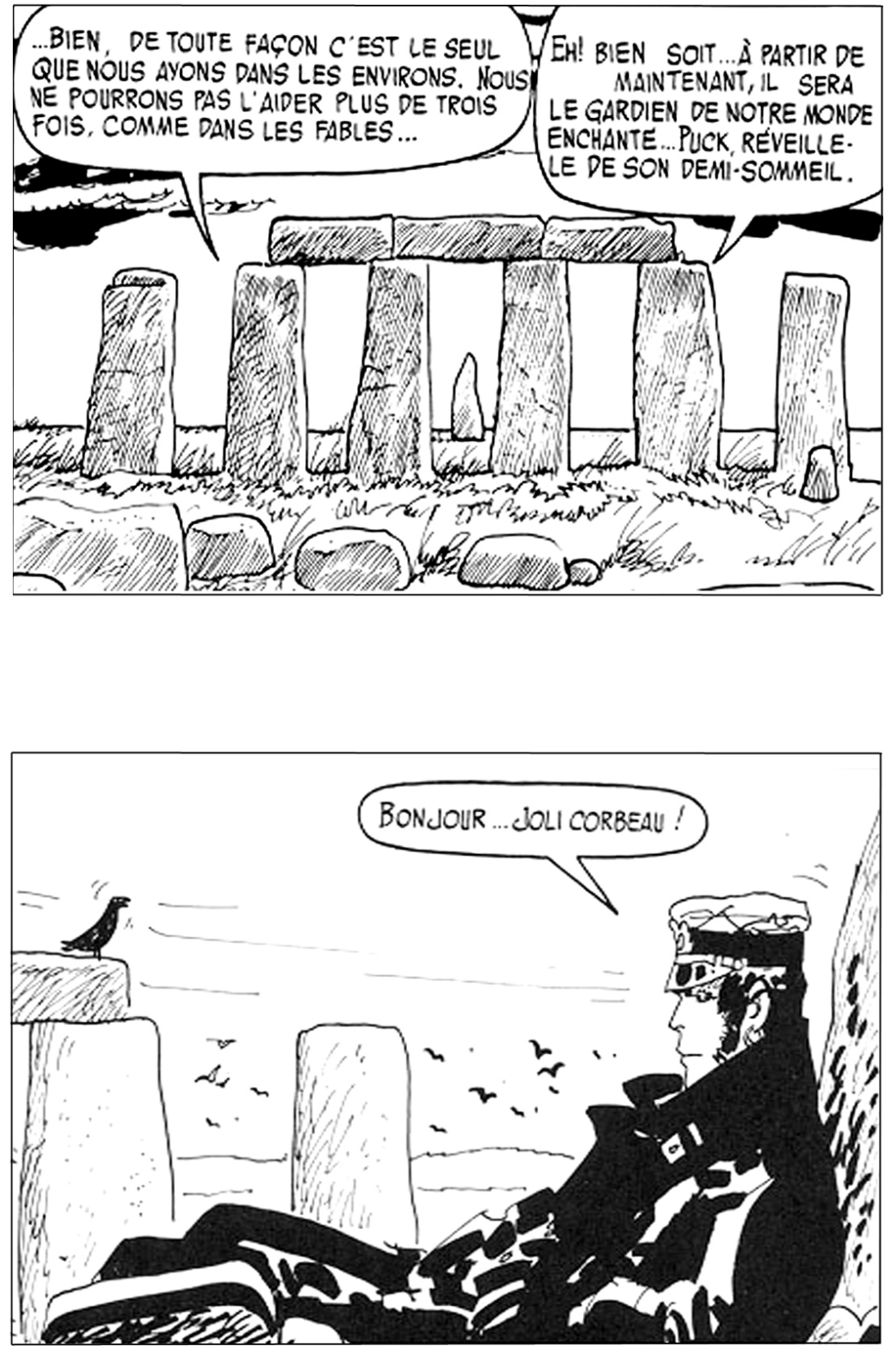

Extraído de H. Pratt, Les Celtiques, Casterman, 2000. 